\title{
A research agenda for information quality assurance in public safety networks: information orchestration as the middle ground between hierarchical and netcentric approaches
}

\author{
Nitesh Bharosa $\cdot$ Marijn Janssen $\cdot$ Yao-Hua Tan
}

Received: 9 January 2009/ Accepted: 15 January 2011/Published online: 5 March 2011

(C) The Author(s) 2011. This article is published with open access at Springerlink.com

\begin{abstract}
One of the key challenges in public safety networks is to ensure a high level of information quality (IQ) during disaster response. Since many evaluation reports on disaster response efforts have revealed instances of poor IQ, both academics and practitioners are in search of information architectures that assure IQ. This article focuses on the hurdles and opportunities for IQ assurance via information architectures. Drawing on two opposing coordination approaches, hierarchical versus netcentric, we suggest adopting a hybrid, information orchestration-based approach for assuring IQ. While hierarchical coordination approaches result in architectures dictating predefined information flows dependent on structures and procedures, netcentric information coordination emphasizes the need for individual self-synchronization driven by events. Even though both architectures have their strengths and weaknesses depending on several contingencies, both include characteristics that hamper IQ assurance for relief workers. Information orchestration offers the middle ground between hierarchical and netcentric approaches and defined as a heterarchical form of information coordination consisting of a specific set of roles and capabilities related to the collection, enrichment, and dissemination of highquality information. Capabilities that need to be developed according to the information orchestration approach constitute a research agenda.
\end{abstract}

\footnotetext{
N. Bharosa $(\bowtie) \cdot$ M. Janssen · Y.-H. Tan

Faculty of Technology, Policy and Management, Delft

University of Technology, Delft, The Netherlands

e-mail: n.bharosa@tudelft.nl

M. Janssen

e-mail: m.f.w.h.a.janssen@tudelft.nl

Y.-H. Tan

e-mail: Y.Tan@tudelft.nl
}

Keywords Disaster management - Information quality · Netcentric orchestration - Public safety networks

\section{Introduction}

In 2005, an advisory committee to the Dutch Ministry of Internal Affairs and Kingdom Relations concluded that relief workers in public safety networks (i.e., police officers, firemen, and ambulance personnel) are too often confronted with two types of problems during multi-agency disaster management: (1) having limited access to information in the network and (2) a lack of information sharing amongst the autonomous relief agencies (ACIR 2005). Three years later, the "All Hands on Deck" workshop including top level government officials and commanders of multiple relief agencies concluded that especially the coordination of information sharing is still a major problem in the Netherlands (ASE 2008). This is not only a problem for relief workers in the Netherlands. Evaluation studies on disaster management efforts around the globe have reported similar issues (e.g., Dawes et al. 2004; Chen et al. 2008). For instance, The National Institute of Standards and Technology (National Institute of Standards and Technology 2005) concluded that "a preponderance of evidence indicates that emergency responder lives were likely lost at the World Trade Center resulting from the lack of timely information sharing between agencies". In the response to the 2004 Tsunami, "mostly, the information was incomplete, yet conclusions had to be drawn immediately" (Samarajiva 2005). "During the response to Hurricane Katrina, the federal government lacked the timely, accurate, and relevant ground-truth information necessary to evaluate which critical infrastructures were damaged, inoperative, or both" (Townsend 2006). 
These examples of poor information quality (IQ) might just be a tip of the iceberg when considering that statistics report that in 2007, 414 natural disasters were reported killing 16,847 persons, affecting more than 211 million others and caused over 74.9 US\$ billion in economic damages (Scheuren et al. 2008). Compared with other problems in disaster management such as political decision-making (Boin et al. 2005), bounded human cognition (Stern 2001), and uncertainty (Argote 1982), the occurrence and prevention of information quality problems is illstudied.

Comfort and Kapucu (2006) already observed that relief workers experienced IQ problems, because the systems used were not able to sufficiently adapt to the changing environment. Taking this observation as a starting point, we add that information architectures based on the hierarchical command and control paradigm do not leverage adaptive information coordination capabilities necessary for assuring IQ in public safety networks. On the other hand, a steadily increasing body of literature advocates the concept of Network-Centric Operations (NCO) as alternative for hierarchical information coordination in public safety networks. Drawing on the strengths and limitations of both approaches, we introduce the concept of information orchestration as means for leveraging adaptive information coordination capabilities necessary for IQ assurance. Information orchestration is broader than simple information sharing, as orchestration capabilities are influenced by the institutional structure, organizational responsibilities, and available technology. Hence, the objective of this article is to add to the research agenda on information systems for public safety networks by elaborating on needed capabilities for information orchestration prior to and during multi-agency disaster response.

This article contributes to existing literatures in three ways. First, it specifies IQ problems during disaster response efforts, and it also exposes the need to ensure that information provision and sharing are adapted to changing circumstances. Second, it elaborates on the strengths and limitations of two contrary approaches for information coordination dilemma in public safety networks. Finally, this article presents an information orchestration framework that constitutes capabilities needed for IQ assurance as avenues for a research agenda.

This article proceeds by elaborating on what we know about IQ problems during disaster response and the coordination of information under such circumstances. Next, we discuss what we need to know and elaborate on the information orchestration concept as means for assuring IQ. This article concludes with a research agenda on which steps we need to undertake to advance information coordination and presents some questions for further research.

\section{Disaster management and poor information quality}

Information quality (IQ) is not a new concept in information systems research and has been studied extensively (e.g., Miller 1996). What is new in the past decade is the explosion in the quantity of information and the increasing reliance by most segments of society on that information (Ballou et al. 2004). IQ is a pervasive concept and a key antecedent in the information systems success (Delone and McLean 1992). The concept of IQ has been studied by multiple scholars (e.g., Strong et al. 1997; Miller 1996; Ballou and Tayi-Kumar 1999). Consequently, several frameworks have been proposed for capturing IQ dimensions (e.g., Redman 1995; Wang and Strong 1996; English 1999), each viewing and treating this concept differently. Usually, scholars do not define what IQ is. Instead they prefer to provide a set of IQ dimensions (or criteria) information should meet. These criteria can be used as benchmarks for measuring the effectiveness of information systems and for developing information architecture arrangements that assure IQ (Miller 1996). However, the number and type of criteria for IQ proposed by scholars differs. For instance, Miller (1996) suggests that IQ has ten dimensions, while Pipino et al. (2002) differentiate sixteen dimensions. A detailed overview of dimension can be found in the article by Strong et al. (1997), who suggest categorization of the dimensions in order to focus on the development of arrangements to assure information quality. The proposed categories are intrinsic, accessibility, contextual, and representational IQ. Using these categories, the next table describes some IQ problems pointed out in literature on disaster response.

Table 1 outlines only a handful of IQ problems encountered by relief workers during disaster management efforts. The relative importance of each IQ category depends on several contingencies during the life cycle of a disaster in which activities, goals, stakeholder involvement, and accompanying information need changes. For instance, in the first hour of disaster management, accessibility of information is the largest concern, whereas the following hours pose problems related to the contextual, intrinsic, and representational characteristics of information. While poor IQ can be a major problem for relief workers, we treat information quality issues as symptoms of non-adaptive information coordination. As discussed by Chen et al. (2008), multiple inputs can be coordinated during a disaster including the task flows (tasks and interdependent relationships), resources, information, decisions (decision roles, rules, and structures), and responders (relationships, team-think, group dynamics organizational dynamics). Because we are primarily interested in improving IQ in the public safety network, we specifically focus on the 
Table 1 Information quality categories and problems pointed out in previous research

IQ category Example an of IQ problem

Accessibility (e.g., availability)

"On the day of landfall, authoritative reporting from the field was extremely difficult to obtain .....as a result, local, state, and federal officials were forced to depend on a variety of conflicting reports from a combination of media, government and private sources, many of which continued to provide inaccurate or incomplete information throughout the day, further clouding the understanding of what was occurring in New Orleans" (Townsend 2006).

The 9/11 case shows that access to data across agency lines also needs to be improved to support interagency coordination (Comfort and Kapucu 2006). "In some cases, needed information existed but was not accessible" (Dawes et al. 2004).

Contextual (e.g., relevancy and timeliness)
During the 9/11 response, only the police officers received relevant information on the building collapse, while this information was valuable for firefighters and ambulance personnel as well (9-11 Commission 2002).

"Sending us very stale situation reports info that has already been updated (earlier) is not as helpful. Is there a way to coordinate the info flow so we don't waste time receiving such old data and you folks don't waste time sending us stuff?" (Christopher and Robert 2006).

Firefighters rushing to the Schiphol Detention Complex received outdated information about the available gates to the area and were delayed in finding the right gate (Onderzoeksraad voor Veiligheid 2006).

Intrinsic (e.g., correctness, consistency, validity and completeness)

In the response to the 2004 Tsunami, "mostly, the information was incomplete, yet conclusions were drawn immediately" (Samarajiva 2005).

"During Katrina, the federal government lacked the timely, accurate, and relevant ground-truth information necessary to evaluate which critical infrastructures were damaged, inoperative, or both" (Townsend 2006).

Representational (e.g., amount of information and format)
When a large-scale disaster happens, a great deal of information occurs in a short period of time (Atoji et al. 2000), resulting in too much information to process (Jenvald et al. 2001) and straining the capacity of the emergency management and communication systems (Manoj and Hubenko Baker 2007).

During $9 / 11$, sometimes valuable information necessary for re-establishing normal operations in non-emergency organizations had been kept only on paper, such as legal files for cases in the process of litigation. This information was either destroyed or made inaccessible due to the closure of buildings that needed thorough inspection or repair before they could be re-occupied (Dawes et al. 2004). coordination of information, referring to the collection, analysis, enrichment, and distribution of information in the network. Considering the types of IQ problems outlined in table 1 , we need to understand the characteristics of the underlying information coordination architecture that allow for or prevent the occurrence of these IQ problems. Accordingly, the next section discusses the hierarchical, command, and control coordination approach on which many existing disaster information coordination architectures are based.

\section{Hierarchical coordination in public safety networks}

\subsection{Background}

Many of the existing information coordination architectures in public safety networks are based on the hierarchical (a.k.a. command and control) coordination approach (see for instance Bigley and Roberts 2001; Hale 1997; Mackenzie et al. 2007). This reflects the belief that the most effective repression operations are carried out under rigid control, exercised convergent with intra-agency authority structures. The major strategic decisions are made at the highest echelons and are filtered down, and more detail is added as they pass through to the lower echelons (top-down/bottom-up principle). Throughout this flow of information, an asymmetry of information load is maintained, often resulting in fragmented situation awareness (cf. Militello et al. 2007). In a hierarchy, the flow of information is coordinated trough adjacent steps, by controlling and directing information to the higher and subordinate echelons (Malone et al. 1987). The advantage of this coordination approach is that the number of interactions and interdependencies between relief workers is often known and limited since the linkages are based on longlasting relationships and procedures. In many public service domains, hierarchical coordination was embraced 
from the start and has been intensified because of the demand for stability, transparency, and accountability in the public sector.

\subsection{Limitations and the need for adaptive information coordination}

Hierarchical coordination assumes that the environment is predictable enough to characterize existing interdependencies and that predefined mechanisms can be designed for various contingencies. While these conditions often exist during non-disaster situations, extreme events will lead to more uncertainty, a greater density of communication and the rate of decision-making increasing particular at lower levels (Kapucu 2006). While hierarchical coordination, characterized by structural features such as standardization, specialization, and formalization, enable the steady, efficient functioning of relief agencies in stable (non-disaster) environments, they also severely limit the flexibility public safety networks need to cope effectively with complex, ambiguous, and unstable task environments (cf. Adler et al. 1999). Weick (1990) postulates that system and task complexities coupled with the need for immediate local adjustments may preclude the possibility of sufficient or timely direction from superior hierarchical positions. In extreme environments, "we need to acknowledge that not all relevant information is known, and that previously known conditions may be in a state of flux" (Kapucu 2006). Moreover, each crisis is different which makes it impossible to predict who will need which information in advance. The ability to adapt to situations is often the factor that makes things work, despite technical constraints, dynamics of the task, and contextual factors (Johansson and Hollnagel 2007). In the case that information needs in the operational environment are unpredictable, adaptability is necessary. We acknowledge that adaptability is both multi-facetted and multi-dimensional, and limit our focus to the "ability of the information coordination architecture to supply the right information at the right time in the right form to the right person, under changing conditions".

Chakravarthy (1982) argues that the higher the level of adaptation, the higher is the environmental complexity that can be handled by the organization, or in this case, the several disaster response teams. We embrace this argument and illustrate its implications for information coordination architectures in Fig. 1.

As illustrated in Fig. 1, highly adaptive information coordination architectures can cope with more uncertainty and thus, cover more information needs than non-adaptive information architectures. We view adaptability as the ability to permit changes in order to better share information and meet the needs. We intentionally use the term "information need" instead of "information demand" since a relief worker may not demand information although he or she can benefit from this information (for instance on the collapse of a building).

From an organization science perspective, adaptation is often the result of an ongoing negotiation between the organization and its environment (March 1991). Corbacioglu and Kapucu (2006) analyzed the cultural, organizational, and technical capacity of five response systems and concluded that the availability of information, its exchange, and its distribution within and among organizational actors is critical for effective response. Using the law of requisite variety Ashby (1958) pointed out that for a given state of the environment, an open system has to be able to respond to changes by adapting, otherwise the ability of the system to survive is reduced. By not adapting to the changing circumstances, an information system can
Fig. 1 The need for adaptive information coordination architectures

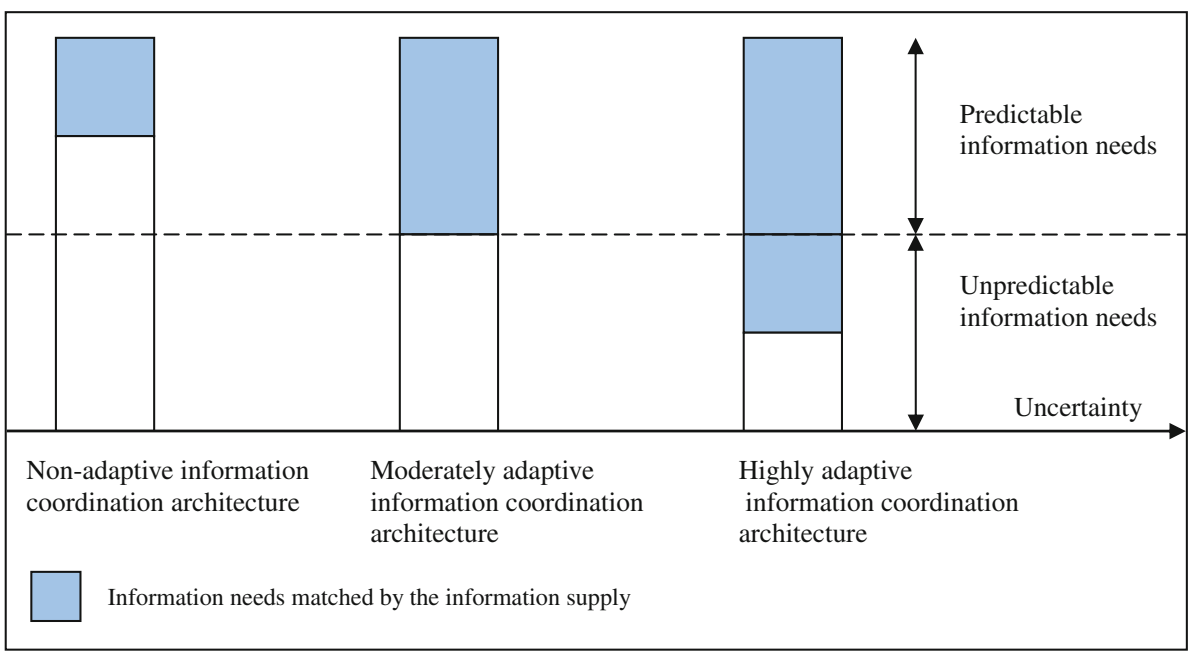


become an obstacle, instead of an enabler, for effective information coordination. Hence, this supports the argument that dealing with unpredictable environments and information needs requires a high level of adaptability in information coordination. Having discussed the limited adaptability of hierarchical-based information coordination architectures, the next section elaborates on the proposed alternative of netcentric information coordination.

\section{Netcentric information coordination in public safety networks}

\subsection{Background on netcentricity}

In the military, a more network oriented coordination model has been advocated called "Network-Centric Operations" or NCO. The term "Network-Centric Operations" (NCO) (also known as "Network-Centric Warfare") comes from the U.S. Department of Defense and was first coined by David Alberts, Art Cebrowski, and John Gartska in a series of CCRP articles starting in 1996. Similar terms have been introduced in other countries as well, including Network Enabled Capability (NEC) in the United Kingdom and Network Based Defense in Sweden. Acknowledging several definitions that have been proposed for NCO (e.g., Van de Ven et al. 2008; Stanovich 2006), one definition that captures it essentials is "military operations that exploit state-of-the-art information and networking technology to integrate widely dispersed human decision makers, situational and targeting sensors, and forces and weapons into a highly adaptive, comprehensive system to achieve unprecedented mission effectiveness", (Naval Studies Board 2000). In theory, the small-unit soldier who can access information and intelligence from all collection sources will be able to employ combat assets such as air support, artillery, and electronic warfare with much more precision, timeliness, and effectiveness than what was possible with past capabilities (Stanovich 2006). Netcentricity emphasizes horizontal communications among peers rather than vertical communications among commanders and subordinates. In essence, NCO harnesses the autonomy of individuals and seeks to empower the individuals (i.e., relief workers) in their ability to adapt to changing circumstances. A higher level of adaptability is assured by leveraging the underling human and technical network capabilities. Four tenets that comprise a description of the purported benefits of adopting NCO (Alberts et al. 2002) are:

- A robustly networked force improves information sharing.

- Information sharing and collaboration enhance the quality of information and shared situational awareness.
- Shared situational awareness enables self-synchronization, and enhances sustainability and speed of command.

- These, in turn, dramatically increase mission effectiveness.

To these four tenets, Alberts (2002) adds that NCO involves both: (1) the provision of vastly increased access to information at all echelons and (2) the redefinition of the relationships among participants in a mission and between commanders and subordinates. NCO predicts a compression of the tactical, operational, and strategic echelons of war and the need to operate seamlessly across organizational boundaries. The main capabilities necessary for leveraging the purported benefits by NCO are decomposed in three domains (Ibid)

1. Physical domain (technical implementation)

- All elements of the force are robustly networked achieving secure and seamless connectivity.

2. Information domain

- Reachback: the force has the capability to collect, share, access, and protect information.

- The force has the capability to collaborate in the information domain, which enables a force to improve its information position through processes of correlation, fusion, and analysis.

- A force can achieve information advantage over an adversary in the information domain.

\section{Cognitive domain}

- The force has the capability to develop and share highquality situational awareness.

- The force has the capability to develop a shared knowledge of commander's intent.

- The force has the capability to self-synchronize its operations.

Until now, academic contributions regarding NCO are scarce and the purported benefits have not yet been tested. Moreover, metrics for evaluating the level of netcentricity (i.e., zero netcentricity versus full netcentricity) are lacking. Yet, relief agency managers are showing increasing interest in the concepts behind $\mathrm{NCO}$, particularly as responders prepare for an increasingly complex threat spectrum in a post-9/11 world (Stanovich 2006). Particularly, the promise of the "four rights": the network supplies the right information at the right time in the right form to the right person attracts some interest in NCO. While we acknowledge that the relief agencies in public safety networks deal with complex, hazardous, and highly unpredictable events comparable to military missions, we need to underline that the heterogeneity in public safety networks may be a hurdle when seeking to leverage the advantages of NCO. Depending on the type and scale of a 
disaster, public safety networks consist of a variable set of agencies, each employing their own information coordination procedures and technologies (Bharosa et al. 2010). Considering the characteristics of public safety networks, we express some concerns when adopting NCO as main approach for configuring information coordination architectures in the next section.

\subsection{Three major concerns regarding netcentric} information coordination in public safety networks

Barnett (1999) and later Groh (2006) have outlined some major concerns regarding netcentricity in warfare, including "ignoring the human dimension" and the "overemphasis on technology". For the domain of disaster management, we postulate three major concerns that need to be considered when (re)designing information coordination architectures in accordance with the netcentric approach. First and foremost is the threat of information overload that may overcome relief workers when they are able to receive information from a large number of network nodes (i.e., other relief workers and sensors). Here, information overload refers to "a cascade of data that exceeds the finite limits of information that can be processed and acted upon by a human being in a stressful and complex multi-tasking environment" (Stanovich 2006). In existing hierarchical information architectures, information overload is mentioned as a problem for relief workers (e.g., Atoji et al. 2000; Jenvald et al. 2001; Manoj and Hubenko Baker 2007). Yet, we are concerned that when having a far larger number of nodes participate in the information coordination process as dictated by netcentric coordination, information overload may occur more often than is the case with hierarchical coordination. A network of nodes is generally incapable of deciding and semantically filtering who needed what and when. In addition, when each individual relief worker is allowed direct access to databases (instead of querying information via the control room or other agency), the tasks of discovering and filtering information from a large dataset may even increase the time needed to access relevant information. The change in distraction created by peripheral and irrelevant information is high and often has the effect of slowing the decisionmaking process, as relief workers must process large amounts of obfuscating and sometimes contradicting information. Moreover, some nodes in the network may actually reduce the overall quality of the information in the network, for instance, when contributing information of low quality (e.g., outdated, irrelevant, and incorrect). Ultimately, information overload may not only delay the relief worker in making timely and effective decisions, it may also make it difficult for the relief worker to filter the right, high-quality information from noise.
The second concern regarding netcentric information coordination is the dilution of decision making and responsibility boundaries (an advantage of hierarchical coordination) when every relief worker has access to all information in the network. This means that relief agency commanders (strategic echelon) may interfere in decisions and actions on the operational level of response, just because the commanders think they know what is happening on the field. As observed by Stanovich (2006), the availability of such a plethora of nearreal-time information often creates the false impression among commanders that they have the same solid and accurate grasp of conditions and situational awareness as the local responders that deal with the incident at the scene.

The third concern is that of bottom-up "freelancing", something that is less problematic when subordinates receive piecewise information (i.e., decisions and instructions), which is the case in hierarchical information coordination. Freelancing is generally defined as "illegitimate improvisation" that is not working toward the goals of strategic level commanders (Mendonca et al. 2004). In this context, freelancing due to available "big picture" or shared situational overview can be considered as a deviation from higher intent that is both unpredictable and unexpected, and such activity presents serious problems to a unified response effort.

\subsection{The coordination dilemma: why can relief agencies not just abandon hierarchical coordination?}

Despite the purported advantages of the NCO approach to coordination, relief agencies are not hastily to abandon their hierarchical approach for coordination. One possible explanation for this is that during non-crisis circumstances, relief agencies work autonomously and operate as independent organizations with the need for tight standards, long-linked process, and pooled information sharing to ensure a clear division of responsibilities, prompt decision processes, and timely action. Hierarchy is used to establish control, specify tasks, allocate responsibilities and reporting procedures, and presumably gain reliability and efficiency in workflow. The standard administrative approach to solving complex problems has been to organize work involving multiple agents and tasks hierarchically (Simon 1996). This approach works reasonably well in routine circumstances when there is time to plan actions, train personnel, identify problems, and correct mistakes. Moreover, governments favor this approach because it allows for high accountability, which is important because the "blame game" after a disaster requires politicians to pinpoint those who were responsible (Boin et al. 2005). 
More reasons that relief agencies could have for not adopting network-centric coordination lie in the far reaching changes that need to be made on all levels of response. Organizations that have adopted a netcentric approach, such as the U.S. military or private companies have struggled to modify hierarchical, control-oriented approaches and to develop organizational structures that are more horizontal and parallel (Alberts and Hayes 2003). Netcentric coordination assumes a high level of uniformity and standardization on multiple levels of response such as in the military, whereas this is often not the case in the domain of multi-agency disaster response. Relief agencies are both autonomous and heterogeneous in their daily operations and serve different objectives. Finally, the three concerns noted in the previous section (information overload, responsibility dilution, and freelancing) underline that the concept of NCO still requires further investigation. The NCO vision is out-of-sync with the current organizational realities of public safety networks.

Hierarchical coordination works fine for daily, routine operations. However, under cumulative stress, hierarchical organizations tend to break down, and personnel are hindered by a lack of information, constraints on innovation, and an inability to shift resources and action to meet new demands quickly (see also Comfort 1999). NCO could substantially reduce information sharing time and improve information access in public safety networks, only if the previously noted concerns are effectively addressed. Therefore, any information disaster information coordination system design should acknowledge that centralized information sharing and coordination is essential for controlling and coordinating efforts in accordance the intentions of decision-makers, while decentralized information sharing and coordination is necessary to adapt tasks in the context of local conditions. While no single decision-maker can control the detailed actions of such a large number of relief workers, the alternative of allowing everyone in the network to collect and disseminate information may be counterproductive in dealing with the disaster situation. Therefore, what we need to know is what kind of hybrid approach to information coordination could retain the strengths of hierarchical and netcentric coordination, while attenuating the limitations of both. Much of previous research, however, has treated both modes of coordination separately or even as two extremes. Our observations from field studies (Bharosa et al. 2010) have inspired us to search for enhancements in the existing information coordination architectures that may leverage the capabilities required for assuring information quality. We coin information orchestration as the concept that offers the middle ground. This concept is discussed next.

\section{Information orchestration: a hybrid approach to information coordination}

\subsection{Elements of orchestration: boundary spanning and mediation}

Having elaborated upon two opposing information architectures in the previous sections, this section argues the need for a hybrid approach to information coordination that retains the strengths of hierarchical and netcentric coordination, while attenuating the limitations of both. We draw on Faraj and Xiao (2006) who challenge much of the traditional approach to coordination and suggest that in settings where work is contextualized and non-routine (e.g., disaster management), traditional models of coordination are insufficient to explain coordination as it occurs in practice. These authors give two conditions under which the traditional coordination theory fails: when expertise is distributed and work highly is contextualized, expertise coordination is required to manage knowledge and skill interdependencies. Also, when it is crucial to avoid error under time pressure, fast-response cross-boundary coordination practices are needed. Both of these conditions apply to disaster management. Hence, looking for a more appropriate definition for coordination, Faraj and Xiao (2006) define coordination as "a temporally unfolding and contextualized process of input regulation and interaction articulation to realize a collective performance". We argue that this definition fits our study of the coordination of information sharing during disasters. Disasters require temporarily unfolding and contextualized coordination mechanisms in which input and resources need to be regulated for high collective performance. Because relief agencies are information intensive, it is just as important to focus on the content of coordination (what is being coordinated) as on the mode of coordination.

Traditional coordination theory emphasizes the how (i.e., the mode) of coordination as opposed to the what (content) and when (circumstances) of coordination (Thompson 1967). This distinction becomes increasingly important in complex and dynamic environments where there is less reliance on formal structure, interdependencies are changing, and work is primarily performed in heterogeneous teams. Scholars such as Powell (1990); Clemons et al. (1993) have studied ways to coordinate organizations other than hierarchies and have also emphasized the need for inter-organizational information sharing, especially in the network form of coordination. Moreover, they have discussed the possibilities for hybrid forms of coordination that are suited for dealing with different conditions. We draw upon this idea, especially since information technology has evolved in such a way that it can support individuals or groups can coordinate information sharing 
beyond organizational boundaries (Lindgren et al. 2008). It is because of this evolution that we propose the concept of information orchestration.

The concept of orchestration is not entirely new as it has been studied in other domains such as e-government (Janssen et al. 2006), value chains (Hinterhuber 2002), and business networks (Busquets 2010). Accordingly, multiple types of orchestrators have been proposed including the workflow, process, information, and network orchestrators. Due to the high level of specialization and distribution of work during disaster management, relief agencies are fragmented by multiple functional, geographical, hierarchical, and professional boundaries. In such contexts, orchestrators are necessary for the coordination of information flows between multiple agencies. Orchestration is often described as a heterarchical, information technology enabled, coordination of information sharing performed by boundary spanners with a specific set of capabilities called similar to mediators (Wiederhold and Genesereth 1997) or brokers (Miles and Snow 1986). The term "heterarchical" is used because there is no hierarchy of processors (active units). Heterarchical control structures have distributed locally autonomous entities that communicate with other entities without the master/slave relationship found in a hierarchical architecture. According to Dilts et al. (1991), the field of distributed computing is a source for a number of justifications for the principles of heterarchical control architectures.

Orchestration is performed by so-called boundary spanners, i.e., individuals who operate at the periphery or boundary of an organization, relating the organization with elements outside it. On a general level, boundary spanning can be seen as the activity of making sense of peripheral information that is perceived relevant to expand the knowledge at the center of a given organizational context (Lindgren et al. 2008). The difference with the traditional form of boundary spanning lies in the high reachback (wide accessibility and geographical reach of the information technology used). As such, orchestration is an information coordination activity aimed at linking new, typically environment-related information to prior knowledge for gaining situational awareness. Essentially, these individuals scan the environment for new information, attempting to determine its relevance vis-à-vis information already assimilated in the organization. In this boundary-spanning process, the individual, the organization, and the environment are parts of a network of interactions and organizational knowledge creation (Cohen and Levinthal 1990). Boundary spanners need to be connected to most of the disaster management network members for high centrality in the network. This level of connectivity is enabled by information technology. As a result of this centrality, they will enjoy positive resource asymmetries (Gnyawali and Madhavan 2001). Based on the theory of structural holes (Burt 1992), the orchestrator bridges the structural holes (gaps in information flows) that exist between multiple relief agencies. By filling the existing structural holes, orchestrators enhance their control of the information that flows between relief agencies and hence can accrue information benefits (Gnyawali and Madhavan 2001). For instance, the orchestrator may have access to information about the resources and capabilities of the police department, or the information needs of fire department. According to Tushman (1977), such information gathering and assimilation is associated with specific boundaryspanning roles at different stages in the innovation process. This allows for the fulfillment of functions beyond that of storage, integration, and brokering. A public safety network can have multiple information orchestrators on different levels. Each orchestrator can fulfill one or more functions. Some proposed functions for information orchestration include coordination of information, information inventory, and interoperation of information services (Janssen and van Veenstra 2005).

\subsection{A framework for information orchestration capabilities}

We define information orchestration as a heterarchical form of coordination supported by a specific set of roles and capabilities related to the collection, enrichment, and sharing of high-quality information. Until now, academic contributions on how to design orchestrators are sparse. Directions can be identified based on the necessary capabilities for adaptation, as provided by the contribution of Gosain et al. (2005). Drawing on their contribution, we conceptualize information orchestration as a set of two arrangements that need to be implemented for adaptive information coordination: advance structuring and dynamic adjustment. Each of these arrangements leverages offensive (preemptive and exploitative) and defensive (protective and corrective) capabilities.

Advance structuring refers to a priori structuring of inter-organizational information flows and inter-connected processes, such that relief agencies can reduce the effort involved in adjusting to the changing task environment. As relief workers do not have to collaborate and share information during routine, non-disaster situations, there is often only a weak relationship between such agencies. Advanced structuring requires long-term relationship building amongst relief agencies prior to and during a disaster. Advance structuring needs to leverage preemptive and protective capabilities for structuring inter-organizational information flows for instance by reducing task interdependence through loose coupling (Tan and Sia 
2006), or mitigating resource dependency by diversifying resource allocations (i.e., creating alternative information sources). Loose coupling reduces the need to coordinate information exchange and flow in a dyadic relationship, while dependency diversification generates alternative options to mitigate overdependence on critical resources. Such capabilities should result in higher adaptability. From an information architecture perspective information, orchestration requires an extra layer is inserted the client and the server (Wiederhold and Genesereth 1997). Examples of capabilities that can be leveraged trough advance structuring include reachback (the ability to access resources that are not locally available) and caching (the ability to freeze data entry modules in applications so that information need not to be lost during (temporary) infrastructure failure.

Complementary to advance structuring, dynamic adjustment involves real-time reconfiguration of inter-organizational information sharing processes and resources in accordance with the changed disaster environment. The primary theoretical basis for dynamic adjustment is the learning-based sense and adapt paradigm (Haeckel 1995). Sambamurthy et al. (2003) suggest that dynamic adjustment is achieved by enhancing feedback in a changing environment through sensing and adapting making it a two-pole strategy. In sensing capability, IT-supported orchestrators become more informed and forward-looking, and have more time to adapt, through feedback, quick learning, and constant environmental scanning. Examples of capabilities that can be leveraged trough dynamic adjustment include proactive sensing (ability to anticipate information needs) and quality feedback (ability to rate the quality of information shared). The following framework captures both sets of arrangements and the necessary capabilities necessary for adaptability and IQ assurance.

According to Fig. 2, advance structuring and dynamic adjustment require four set of capabilities for assuring adaptive information sharing and coordination. We argue that information orchestration will allow subordinate relief agencies to adjust and adapt quickly and easily to deal with changing situations or unforeseen events and circumstances. If the proposed capabilities are leveraged, information orchestration can retain the strengths (defined command relationships, efficiency, and control) of a bureaucratic hierarchy, enabling preplanning in the more predictable aspects of disaster response, yet also permit the adaptability needed to fulfill information needs during dynamic and unstable disaster situations.

\subsection{Capabilities needed for information quality assurance}

According to the information-processing paradigm (Galbraith 1973), each coordination (i.e., orchestration) mechanism needs to be endowed with a specific informationprocessing capability and must be matched to the information-processing demands of the environment or needs generated by the interdependence of work units. In order to deal with the characteristics of a disaster, information orchestrators need to have a range of capabilities in order to adapt and assure IQ. Moreover, one information orchestrator would not be able to coordinate all the possible information flows in a disaster management network. The exact number of information orchestrators depends on several contingencies. Several information orchestrators may be required for any given disaster situation. A capability is a set of specific an identifiable processes (Eisenhardt and Martin 2000). These capabilities will allow the orchestrator to adaptively match information demand and supply in accordance with the situation at hand. Depending on these capabilities, orchestrators can have a reactive or proactive role in the information-sharing process. For instance, dealing with trusted orchestrators may encourage database owners to participate in information sharing to a greater extent than they would if all participants would need to be granted file-level access privileges. In this way, the hurdles of security and privacy can be addressed. The following table summarizes the necessary capabilities for an information orchestrator in public safety networks.

We postulate that information architectures for assuring high information quality need to realize information orchestration capabilities shown in Table 2. The capabilities will enhance adaptability in a number of ways. For instance, the capability to compose new web services on
Fig. 2 Information orchestration framework for public safety networks

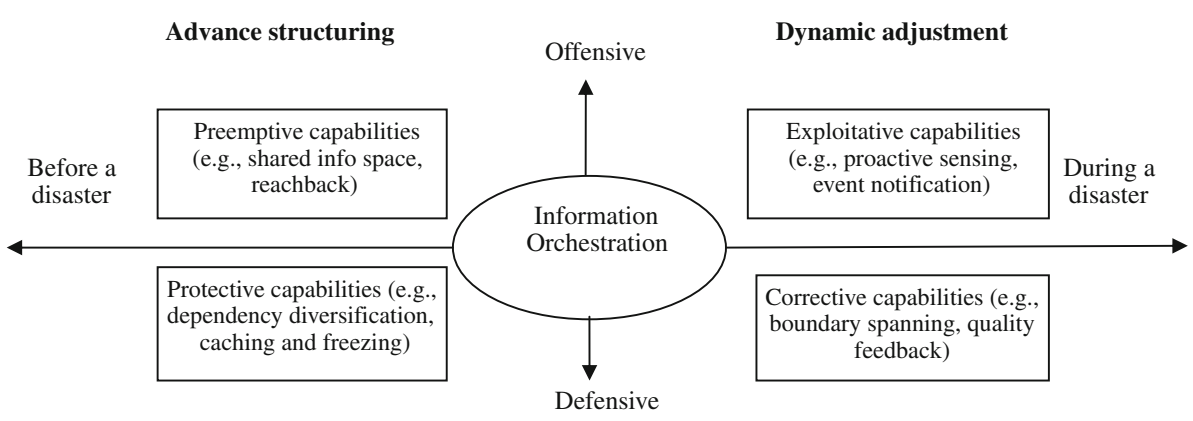


Table 2 Capabilities needed for assuring information quality in public safety networks

\begin{tabular}{|c|c|c|c|}
\hline Necessary capability & Type & Example & Targeted hurdles \\
\hline Quality auditing & Preemptive & $\begin{array}{l}\text { Information quality checks across several } \\
\text { relief agencies and governmental } \\
\text { agencies. }\end{array}$ & $\begin{array}{l}\text { Incorrect and outdated information in } \\
\text { agency data sources. }\end{array}$ \\
\hline Boundary spanning & Corrective & $\begin{array}{l}\text { Integrate demand and supply across } \\
\text { different agencies for specific } \\
\text { information objects (need to now, have } \\
\text { to know etc). }\end{array}$ & $\begin{array}{l}\text { Trust and security, the autonomy of } \\
\text { agencies, bridging interdependencies. }\end{array}$ \\
\hline Information libraries & Preemptive & $\begin{array}{l}\text { Define library containing information } \\
\text { based on the experience from previous } \\
\text { disasters together with some field } \\
\text { experts. Uncertainties within a domain } \\
\text { may be captured by a formal model. }\end{array}$ & $\begin{array}{l}\text { Rapid access to knows, information that is } \\
\text { already available somewhere is being } \\
\text { searched for somewhere else, } \\
\text { uncertainty. }\end{array}$ \\
\hline Web-service composition & Corrective & $\begin{array}{l}\text { Rapid composition of new information } \\
\text { web service in order to accommodate } \\
\text { new information need. }\end{array}$ & $\begin{array}{l}\text { Dealing with unknowns or unprecedented } \\
\text { information needs. }\end{array}$ \\
\hline Enrichment & Corrective & $\begin{array}{l}\text { For instance completing and updating of } \\
\text { situation reports. }\end{array}$ & Incomplete or inaccurate information. \\
\hline Anticipation (e.g., via simulation) & Exploitative & $\begin{array}{l}\text { Extrapolation and prediction of the event/ } \\
\text { risk variables in order to anticipate } \\
\text { information needs. Anticipate what may } \\
\text { happen and which reaction would be } \\
\text { appropriate (Rosen 1985). The next } \\
\text { time we encounter A (or a circumstance } \\
\text { similar to A), we will be prepared, and } \\
\text { more likely to react adequately. }\end{array}$ & $\begin{array}{l}\text { The simple ordering of options according } \\
\text { to the probability that they would be } \\
\text { relevant immensely decreases the } \\
\text { complexity of decision-making, since } \\
\text { we would only need to pay attention to } \\
\text { the most relevant circumstances. }\end{array}$ \\
\hline Information categorization & Protective & $\begin{array}{l}\text { Define the relevancy level of information } \\
\text { (e.g., need to know for all, police only, } \\
\text { nice to know etc.). }\end{array}$ & Information over or under load. \\
\hline Expertise gathering and consultation & Corrective & $\begin{array}{l}\text { Keep and maintain a list of experts on } \\
\text { specific information classes and call } \\
\text { upon their services when needed or } \\
\text { errors in data or knowledge need to be } \\
\text { identified. }\end{array}$ & $\begin{array}{l}\text { Validation of information and availability } \\
\text { of tacit information. }\end{array}$ \\
\hline Reachback & Preemptive & $\begin{array}{l}\text { Maximize the ability to access } \\
\text { information resources that are not } \\
\text { locally available (e.g., building } \\
\text { structures, ship container content info). }\end{array}$ & Information availability, response time. \\
\hline Information quality feedback/tagging & Exploitative & $\begin{array}{l}\text { Add meta-data to existing information } \\
\text { about the source, relevancy, } \\
\text { completeness and timelines. The meta- } \\
\text { data should indicate the quality level of } \\
\text { the information. }\end{array}$ & $\begin{array}{l}\text { Knowing about the quality of information } \\
\text { (based on the tags) relief workers can } \\
\text { decide themselves if they will act upon } \\
\text { the information or wait for/request } \\
\text { updated/enriched information. }\end{array}$ \\
\hline
\end{tabular}

the fly will allow information orchestrators to quickly adapt their application service portfolio to new information needs. In addition, the capability to simulate and extrapolate events will allow orchestrators to predict emerging information demands, again allowing for adaptation of the service portfolio. Domain specialization avoids the tendency to have committees and their compromises drive software specification. The information-processing tasks of orchestrators include accessing of appropriate resources, data selection, format conversion, bringing data to common abstraction levels, matching and integration of information from distinct sources, and preparing information and descriptive meta-information for relief worker customer's workstations, including focusing, filtering, and summarizing. The general objective is to match the demand for information as much as possible and in accordance with the situational circumstances (e.g., if a building will collapse and the relief worker does not know this, this information should be pushed to the relief worker regardless of the demand, whether or not the relief worker demanded this information explicitly). Ultimately, information orchestrators must understand what information is pertinent, what is peripheral, and what is extraneous. They also must determine what agencies are the most reliable sources (for 
Table 3 Comparison between three coordination approaches

\begin{tabular}{|c|c|c|c|}
\hline & Traditional approaches & Information orchestration & $\mathrm{NCO}$ \\
\hline Main coordination form & Hierarchical coordination & Heterarchical coordination & Netcentric coordination \\
\hline Roles & $\begin{array}{l}\text { One or multiple predefined } \\
\text { individuals or groups }\end{array}$ & $\begin{array}{l}\text { Role and specific information } \\
\text { sharing and coordination }\end{array}$ & $\begin{array}{l}\text { Network, everyone can push, pull, } \\
\text { and process information }\end{array}$ \\
\hline Information flows & $\begin{array}{l}\text { Follows the hierarchical chain of } \\
\text { command (grip levels) }\end{array}$ & $\begin{array}{l}\text { Situation and need driven } \\
\text { dissemination }\end{array}$ & Widespread dissemination \\
\hline Network configuration & $\begin{array}{l}\text { Hub and spoke, publish and } \\
\text { subscribe }\end{array}$ & $\begin{array}{l}\text { Smart pull and smart push, } \\
\text { information posting }\end{array}$ & Relational \\
\hline Interdependencies & Pooled & Sequential & Reciprocal \\
\hline Triggers & Input/output, procedures & Events and demand & Events \\
\hline Coordination principles & $\begin{array}{l}\text { Coordination by standards plan, } \\
\text { routines, meetings. }\end{array}$ & $\begin{array}{l}\text { Advanced structuring (e.g., access } \\
\text { to information pool) and } \\
\text { dynamic adjustment (e.g., } \\
\text { coordination by feedback) }\end{array}$ & $\begin{array}{l}\text { Mutual adjustment and } \\
\text { improvisation }\end{array}$ \\
\hline Information sources & $\begin{array}{l}\text { Agency specific, intra- agency } \\
\text { systems }\end{array}$ & $\begin{array}{l}\text { Variety of information sources, } \\
\text { inter-agency data access }\end{array}$ & $\begin{array}{l}\text { All possible sources need to be } \\
\text { accessible }\end{array}$ \\
\hline Service portfolio & Application depended, static, fixed & On the fly service composition & Actor/agency specific \\
\hline Mode of operation & $\begin{array}{l}\text { Reactive (push required } \\
\text { information) }\end{array}$ & $\begin{array}{l}\text { Proactive and protective } \\
\text { (anticipate information needs) }\end{array}$ & Reactive \\
\hline Coupling of elements & Tight & Tight with slack & Loose \\
\hline
\end{tabular}

instance based on their respective reputations), and how those agencies can provide that information, when it is needed, and in the format required. The following table positions information orchestration to the previously discussed coordination approaches.

Table 3 presents the differences between the three main coordination approaches we discussed in this paper, where information orchestration is aimed at taking leveraging the advantages hierarchical coordination (e.g., clear authority structure, standardization, specialization, and formalization), and network approaches (e.g., reachback, adaptability, and self-synchronization). Compared with the hierarchical form of information coordination, netcentric coordination, and information orchestration are not studied much and pose interesting questions for further research. We discuss some of these questions in the next section.

\section{A research agenda for IQ assurance in public safety networks}

Policy makers and information system architects in public safety networks face a dilemma. During normal/non-crisis situations, there exist a need for tight structuring, formal coordination, and top-down decision-making to ensure a clear division of responsibilities, formalized procedures, and accountability. While these characteristics can be considered as the advantages of hierarchical coordination, during a disaster situation, there is a competing need to rely on network-centric structures, including adaptive information flows, network wide information access (reachback), and ad hoc information sharing. While network-based coordination promises some major benefits compared to hierarchical approaches (e.g., higher adaptability, faster information sharing, and shared situational awareness), we see that the realization of such approaches in practice is still missing. Reasons for this include the major technical, organizational, and training investments needed to leverage the promised benefits of netcentricity. Much of previous research, however, has treated both modes of coordination separately or even as two extremes. In the meantime, poor IQ seems to be a recurring issue during disaster response efforts. Therefore, this article underlines need for a hybrid approach to information coordination that retains the strengths of hierarchical and netcentric coordination, while attenuating the limitations of both.

Our observations from field studies (Bharosa et al. 2010) have inspired us to search for minor enhancements in the existing, hierarchical information coordination architectures that may leverage the capabilities required for assuring information quality. We propose information orchestration such as set of minor enhancements to existing information coordination architectures that needs to put on the research agenda on assuring IQ in public safety networks. With information orchestration, the ability to adapt can be leveraged by designing preemptive and protective arrangements (advance structuring) together with exploitative and corrective arrangements (dynamic adjustment). We argue that given the current state of information 
technology and the complexity of the tasks during disasters, relief workers should not be burdened with the task of seeking out information sources and disseminating information in the network. This task of finding structured or unstructured information is best left to an information orchestrator which interacts with information services of various agencies and takes care of the information needs that go beyond the boundary of a single agency. In doing so, such an orchestrator requires capabilities to prioritize, find, combine and evaluate information, and share it with the parties for whom it may be important.

The concept of orchestration and its implications for information coordination during disaster management is not fully crystallized yet and provides directions for further research. The research agenda contains several ill-studied issues, challenging researchers with several backgrounds (i.e., technical, social, and organizational). Research needs to focus on the specification, realization, and evaluation of hybrid information coordination approach such as information orchestration. The exact form and configuration of information orchestrators in all echelons of public safety networks is still unclear. Important research questions that need to be addressed in further research include: how much of the coordination problem is within agencies, how much across, and to what degree are the two interrelated? Which information categories and flows should be orchestrated? How do a team of orchestrators work together coherently? The set of capabilities discussed in our information orchestration framework can help focusing on the development of technical functionalities, roles, and procedures that are needed to assure IQ.

Considering this research agenda stating what we need to know, some directions are also provided on how we need to get there. We argue that scholars need to conduct more field studies on disaster management efforts. As field studies provide rich but abstract data, scholars should aim to triangulate the findings of multiple data collection instruments. For instance, the observation of disaster response exercises and immediate surveying of relief workers after the exercise can be very useful in the data collection process, especially if data is conducted in a longitudinal fashion. This approach to data collection would require closer collaboration between the scholars and the organizers of disaster management exercises. Moreover, in our experience, scholars need to collaborate with exercise organizers in order to obtain data via different channels and $\log$ information system use, an opportunity that is often missed as organizers do not see the need for collecting exercise data. The collected data from field studies could help academics in pinpointing information sharing and coordination bottlenecks, which in turn are necessary for the further development and prototyping of information orchestrators and their embedding in information coordination architectures. Finally, quasi-experimentation, for instance using interactive gaming sessions with real relief workers, holds potential value for testing and fine-tuning the roles and capabilities of orchestrators together their contribution to addressing IQ issues.

Open Access This article is distributed under the terms of the Creative Commons Attribution Noncommercial License which permits any noncommercial use, distribution, and reproduction in any medium, provided the original author(s) and source are credited.

\section{References}

9-11 Commission (2002) Final report of the National Commission on Terrorist Attacks Upon the United States, Official Government Edition. Retrieved from www.9-11commission.gov/report/911 Report.pdf

ACIR (2005) De vrijblijvendheid voorbij. Op naar een effectieve multidisciplinaire informatievoorziening bij grootschalig gezamenlijk optreden in onze gedecentraliseerde eenheidsstaat. The Hague. doi:www.minbzk.nl/contents/pages/38082/vrijblij vendheid_voorbij_03_05.pdf

Adler PS, Goldoftas B, Levine DI (1999) Flexibility versus efficiency? a case study of model changeovers in the toyota production system. Org Sci 10:43-68

Alberts DS, Hayes RE (2003) Power to the edge: Command and control in the information age, vol 18. CCRP Publication Series, Washington

Alberts DS, Garstka JJ, Stein FP (2002) Network-centric warfare: Developing and leveraging information superiority, vol 2, 2nd edn. CCRP Publication Series, Washington

Argote L (1982) Input uncertainty and organizational coordination in hospital emergency units. Admin Sci Quart 27(3):420-434

ASE (2008) Alle hens on deck. Report of an accelarated solutions enviroment session on public safety in the Netherlands (in Dutch). Retrieved from www.minbzk.nl.

Ashby RW (1958) Requisite variety and its implications for the control of complex systems. Cybernetica 1(2):83-99

Atoji Y, Koiso T, Nishida S (2000) Information filtering for emergency management. Paper presented at the IEEE international workshop on robot and human communication osaka, 27-29, September 2000

Ballou DP, Tayi-Kumar G (1999) Enhancing data quality in data warehouse environments. Commun ACM 42(1):73-78

Ballou DP, Madnick S, Wang RY (2004) Assuring information quality. J Manage Info Syst 20(3):9-11

Barnett TP (1999) Seven deadly sins of network-centric warfare. In: USNI Proceedings, 1999. doi:www.nwc.mil/wardept/7deadl 1.htm

Bharosa N, Lee Y, Janssen M (2010) Challenges and obstacles in information sharing and coordination during multi-agency disaster response: propositions from field exercises. Inf Syst Front 12(1):49-65

Bigley GA, Roberts KH (2001) The incident command system: high reliability organizing for complex and volatile task environments. Acad Manage 44(6):1281-1300

Boin A, 't Hart P, Stern E, Sundelius B (2005) The politics of crisis management: public leadership under pressure. Cambridge University Press, England

Burt RS (1992) Structural holes. Harvard University Press, Cambridge 
Busquets J (2010) Orchestrating smart business network dynamics for innovation. European Journal of Information Systems forthcomming paper

Chakravarthy BS (1982) Adaptation: a promising metaphor for strategic management. Acad Manage Rev 7(1):35-44

Chen R, Sharman R, Rao R, Upadhyaya S (2008) An exploration of coordination in emergency response management. Commun ACM 51(5):66-73

Christopher C, Robert B (2006) Disaster: hurricane Katrina and the failure of homeland security. Macmillan Publishers, New York

Clemons E, Reddi S, Row M (1993) The impact of information technology on the organization of economic activity: the "move to the middle" hypothesis. J Manage Info Syst 10(2):9-35

Cohen WM, Levinthal DA (1990) Absorptive capacity: a new perspective on learning and innovation. Admin Sci Quart 35:128-152

Comfort L (1999) Shared risk: complex systems in seismic response. Pergamon Press, New York

Comfort L, Kapucu N (2006) Inter-organizational coordination in extreme events: the world trade center attacks, September 11, 2001. Nat Haza 39(2):309-327

Corbacioglu S, Kapucu N (2006) Organisational learning and selfadaptation in dynamic disaster environments. Disasters 30(2):212-233

Dawes S, Creswell A, Cahan B (2004) Learning from crisis: lessons in human and information infrastructure from the world trade center response. Soc Sci Com Rev 22(1):52-66

Delone W, McLean E (1992) Information systems succes: the quest for the dependent variable. Info Syst Res 3(1):60-95

Dilts DM, Boyd NP, Whorms HH (1991) The evolution of control architectures for automated manufacturing systems. J Manuf Syst 10(1):79-93

Eisenhardt KM, Martin JA (2000) Dynamic capabilities: what are they? Strata Manag J 21(10-11):1105-1121

English L (1999) Improving data warehouse and business information quality. Wiley \& Sons, New York

Faraj S, Xiao Y (2006) Coordination in fast-response organizations. Manage Sci 52(8):1155-1169

Galbraith J (1973) Designing complex organizations. AddisonWesley, Reading, MA

Gnyawali DR, Madhavan R (2001) Cooperative networks and competitive dynamics: a structural embeddeness perspective. Acad Manage Rev 26(3):431-445

Gosain S, Malhotra A, Sawy OAE (2005) Coordinating for flexibility in e-business supply chains. J Manage Info Syst 21(3):7-45

Groh JL (2006) Network-centric warfare: just about technology? In: Bartholomees JB (ed) U.S. Army war college guide to national security policy and strategy, 2nd edn. Department of National Security and Strategy, Carlistle Barracks, pp 373-391

Haeckel SH (1995) Adaptive enterprise: creating and leading senseand-respond organizations. Harvard Business School Press, Boston

Hale J (1997) A layered communication architecture for the support of crisis response. J Manage Info Syst 14(1):235-255

Hinterhuber A (2002) Value chain orchestration in action and the case of the global agrochemical industry. Long Range Plan 35(6): $615-635$

Janssen M, van Veenstra A (2005) Stages of growth in e-government: an architectural approach. The Elect J e-Government 3(4): $193-200$

Janssen M, Gortmaker J, Wagenaar RW (2006) Web service orchestration in public administration : challenges, roles, and growth stages. Infor Syst Manage 23(2):44-55

Jenvald J, Morin M, Kincaid JP (2001) A framework for web-based dissemination of models and lessons learned from emergency- response exercises and operations. Int J Emerg Manage 1(1): $82-94$

Johansson B, Hollnagel E (2007) Pre-requisites for large scale coordination. Cogn Tech Work 9:5-13

Kapucu N (2006) Interagency communication networks during emergencies: boundary spanners in multiagency coordination. Amer Rev Public Admin 36(2):207-225

Lindgren R, Andersson M, Henfridsson O (2008) Multi-contextuality in boundary-spanning practices. Info Syst J 18(6):641-661

Mackenzie C, Fu-Ming Hu P, Fausboll C, Nerlich M, Benner T, Gagliano D, Whitlock W, Lam D, Xiao Y (2007) Challenges to remote emergency decision-making for disasters or homeland security. Cogn Tech Work 9:15-24

Malone T, Yates J, Benjamin R (1987) Electronic markets and electronic hierarchies. Commun ACM 30:484-497

Manoj BS, Hubenko Baker A (2007) Communication challenges in emergency response. Commun ACM 50(3):51-53. doi: $10.1145 / 1226736.1226765$

March J (1991) Exploration and exploitation in organization-al learning. Organ Sci 2:71-87

Mendonca S, Pina e Cunha M, Kavo-Oja J, Ruff F (2004) Wild cards, weak signals and organisational improvisation. Futures 36(2): 201-218

Miles RE, Snow CC (1986) Organizations: new concepts for new forms. California Manage Rev 28(3):62-73

Militello LG, Patterson ES, Bowman L, Wears R (2007) Information flow during crisis management: challenges to coordination in the emergency operations center. Cogn Tech Work 9:25-31

Miller H (1996) The multiple dimensions of information quality. Info Syst Manage 13(2):79-82

National Institute of Standards and Technology (2005) Federal building and fire safety investigation of the world trade center disaster: The emergency response operation. Retrieved from http://wtc.nist.gov/pubs/

Naval Studies Board (2000) Network-centric naval forces: a transition strategy for enhancing operational characteristics. National Academy Press, Washington DC

Onderzoeksraad voor Veiligheid (2006) Brand Cellen complex Schiphol-Oost (in Dutch). The Hague. Retrieved from http://www.onderzoeksraad.nl/en/

Pipino LL, Lee YW, Wang RY (2002) Data quality assessment. Commun ACM 45(4):211-218

Powell WW (1990) Neither market nor hierarchy: network forms of organization. In: Slaw B (ed) Research in organizational behaviour, vol 12. JAI, Greenwich, pp 295-336

Redman (1995) Improve data quality for competitive advantage. Sloan Manage Rev 36(2):99-107

Rosen R (1985) Anticipatory systems: philosophical, mathematical and methodological foundations. Pergamon Press, Oxford

Samarajiva R (2005) Mobilizing information and communications technologies for effective disaster warning: lessons from the 2004 tsunami. New Media Soc 7(6):731-747

Sambamurthy V, Bharadwaj A, Grover V (2003) Shaping agility through digital options: Reconceptualizing the role of information technology in contemporary firms. MIS Quarterly 27(2):237-263

Scheuren J-M, Waroux J-M, Below R, Guha-Sapir D (2008) The numbers and trends 2007. Annual Disaster Statistical Review 2 (2). doi:http://www.emdat.be/Documents/Publications/

Simon HA (1996) The sciences of the artificial, 3rd edn. MIT Press, MA, Cambridge

Stanovich M (2006) Network-centric emergency response: the challenges of training for a new command and control paradigm. J Emerg Manage 4(2):57-64

Stern EK (2001) Crisis decisionmaking: a cognitive-institutional approach. Copy Print, Stockholm 
Strong DM, Lee YW, Wang RY (1997) Data quality in context. Commun ACM 40(5):103-110

Tan C, Sia S (2006) Managing flexibility in outsourcing. J Assoc Info Syst 7(4):179-206

Thompson JD (1967) Organizations in action. McGraw-Hill, New York

Townsend FF (2006) The federal response to hurricane Katrina: lessons learned. Retrieved from http://library.stmarytx.edu/ acadlib/edocs/katrinawh.pdf

Tushman ML (1977) Special boundary roles in the innovation process. Admin Sci Quart 22:587-605
Van de Ven J, Van Rijk R, Essens P, Frinking E (2008) Network centric operations in crisis management. In: Fiedrich F, Van de Walle B (eds) 5th International ISCRAM Conference, Washington, DC, USA, 2008

Wang RY, Strong DM (1996) Beyond accuracy: what data quality means to data consumers. J Manage Info Syst 12(4):5-34

Weick KE (1990) The vulnerable system: an analysis of the tenerife air disaster. J Manage 16:571-593

Wiederhold G, Genesereth M (1997) The conceptual basis for mediation services. IEEE Expert 12(5):38-47 